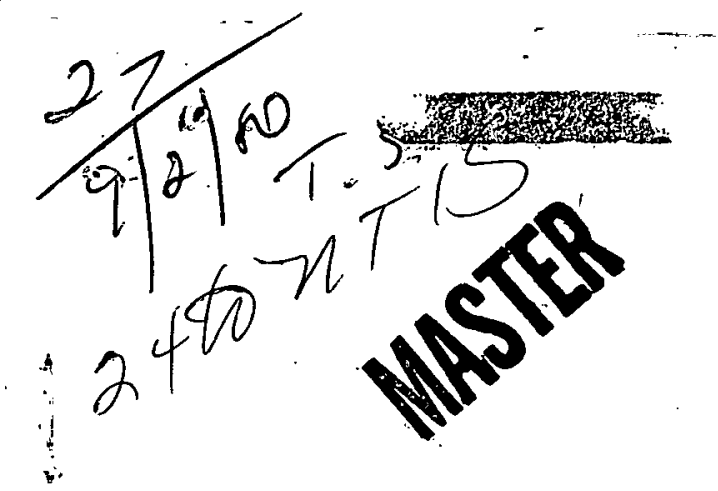

BDX-613-2458

\title{
Plasma Etchback of Multilayer Printed Wiring Boards
}

\author{
By F. L. Gentry
}

Published June 1980

Final Report

Prepared for the United States Department of Energy Under Contract Number DE-ACO4-76-DPO0613.

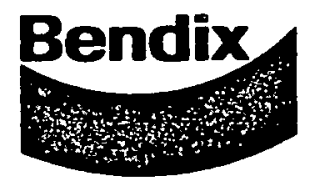

Kansas City

Division 


\section{DISCLAIMER}

This report was prepared as an account of work sponsored by an agency of the United States Government. Neither the United States Government nor any agency Thereof, nor any of their employees, makes any warranty, express or implied, or assumes any legal liability or responsibility for the accuracy, completeness, or usefulness of any information, apparatus, product, or process disclosed, or represents that its use would not infringe privately owned rights. Reference herein to any specific commercial product, process, or service by trade name, trademark, manufacturer, or otherwise does not necessarily constitute or imply its endorsement, recommendation, or favoring by the United States Government or any agency thereof. The views and opinions of authors expressed herein do not necessarily state or reflect those of the United States Government or any agency thereof. 


\section{DISCLAIMER}

Portions of this document may be illegible in electronic image products. Images are produced from the best available original document. 
This report was prepared as an account of work sponsored by the United States Government. Neither the United States nor the United States Department of Energy, nor any of their employees, nor any of their contractors, subcontractors, or their employees, makes any warranty, express or implied, or assumes any legal liability or responsibility for the accuracy, completeness or usefulness of any information, apparatus, product or process disclosed, or represents that its use would not infringe privately owned rights.

Printed in the United States of America

Available From the National Technical Information Service, U.S. Department of Commerce, 5285 port Royal Road, Springfield, Virginia 22161.

Price: . Microfiche $\$ 3.00$

Paper Copy $\$ 4.00$ 
$\mathrm{BDX}-613-2458$

Distribution Category UC-38

PLASMA ETCHBACK OF MULTILAYER

PRINTED WIRING BOARDS

By F. L. Gentry

Published June 1980

Final Report

F. L. Gentry, Project Leader

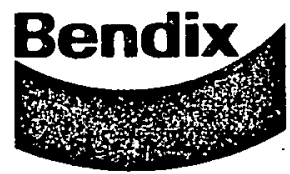

\section{Kansas City Division}

BISTRIBUTION GF TIHS DOCURAEAT IS UAUMILEB 
PLASMA ETCHBACK OF MULTILAYER PRINTED WIRING BOARDS

BDX-613-2458, Final Report, Published June 1980

Prepared by F. L. Gentry

Removal of epoxy smear and glass fiber protrusions in multilayer printed wiring board holes was investigated. Gas plasma techniques, using a mixture of carbon tetrafluoride and oxygen, removed the epoxies; however, the glass fibers were not affected.

$T W L / d j b$

This report was prepared as an account of work sponsored by the United States Government. Neither the United States, nor the United States Department of Energy, nor any of their employees. nor any of their contractors, subcontractors, or their employees. makes any warranty, expressed or implied or assumes any legal liability or responsibility for the accuracy, completeriess or usefulness of any information, apparatus, product, or process disclosed, or represents that its use would not infringe privately owned rights.
The Bendix Corporation Kansas City Division P. O. Box 1159 Kansas City, Missouri 64141
A prime contractor with the United States Department of Energy under Contract Number DE-AC04-76-DPOO613 


\section{CONTENTS}

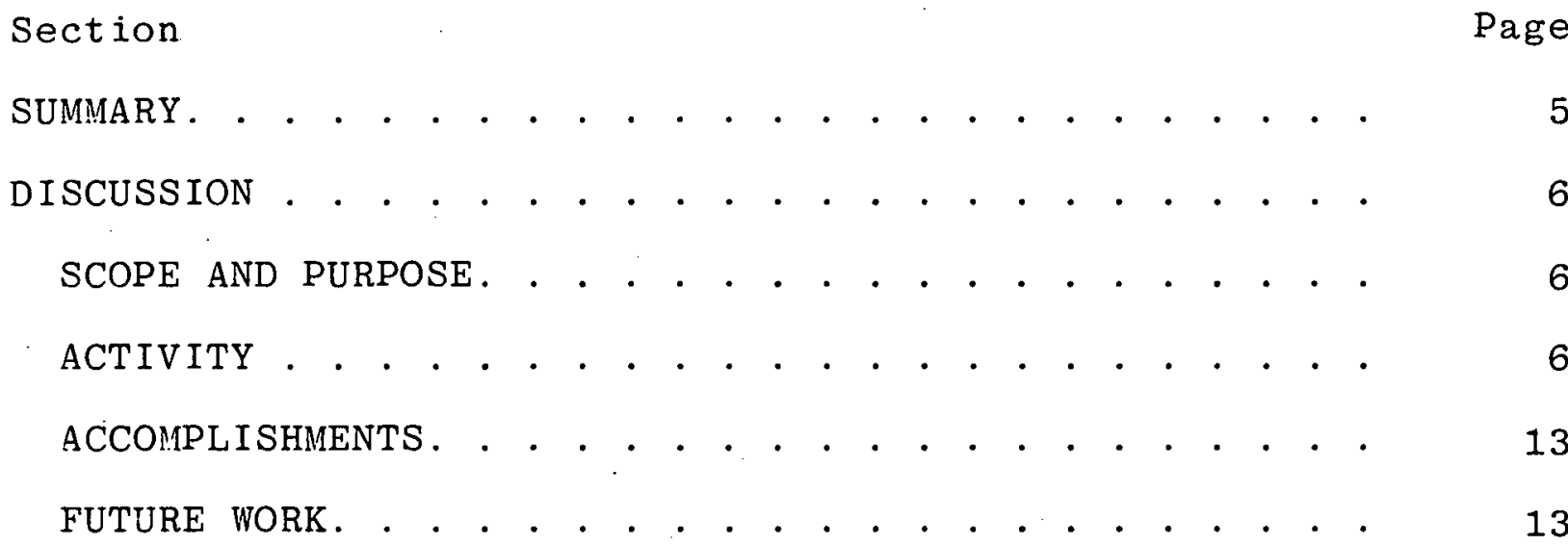




\section{ILLUSTRATIONS}

Figure

Page

1

Multilayer PWB Plasma Etched for 10 Minutes With 30 Percent $\mathrm{CF}_{4} / 70$ Percent $\mathrm{O}$ (Polaroids). . . . . . . . . . . . .

Multilayer PWB Plasma Etched for 15 Minutes With 30 Percent $\mathrm{CF}_{4} / 70$ percent $\mathrm{O}$ (Polaroids). . . . . . . . . . . . . . . .

Multilayer PWB Plasma Etched for 30 Minutes With 30 Percent $\mathrm{CF}_{4} / 70$ Percent $\mathrm{O}$ (Polaroids). . . . . . . . . . . . . . .

Multilayer PWB Plasma Etched for 15 Minutes With 50 Percent $\mathrm{CF}_{4} / 50$ Percent $\mathrm{O}$ (Polaroids). . . . . . . . . . . . . .

Multilayer PWB Plasma Etched for 15 Minutes With Oxygen Only (Polaroids) . . . . . . .

Cross Section of Plated-Through Hole After Plasma Etching and HF Rinse to Remove Glass Fibers (Polaroid). . . . . . . . . .

Effects of Plasma on Surface of Triazine Laminates (Polaroids). . . . . . . . . 
Epoxy smear in multilayer printed wiring board holes must be removed to ensure a continuous electrical connection between the plated-through holes and internal circuitiy. Chromic and hydrofluoric acids are used to etch both the epoxy smear and glass fiber protrusions. Intended to decompose the smeared polymer into a form that can be rinsed away with water, these solutions are toxic, are unpleasant to work with, create significant waste disposal'problems, and are unpredictable in etch rates. The possibility of removing this epoxy/glass smear using plasma techniques was investigated.

While plasmas can be used to etch organic materials such as the epoxies, the glass fibers are essentially unaffected. Because of this limitation, a complete etchback operation involving removal of both the epoxy and glass fibers cannot be performed with the use of a plasma. 


\section{DISCUSSION}

\section{SCOPE AND PURPOSE}

At Bendix Kansas City, etchback of multilayer printed wiring boards (PWBs) using wet chemical processes is performed for the removal of epoxy and glass fibers from the internal conductors within the plated-through holes before plating. The use of plasma techniques to remove drill smear in multilayer PWBs recently has been appearing in literature and technical papers. Some reports imply that plasma techniques using carbon tetrafluoride $\left(\mathrm{CF}_{4}\right)$ and oxygen (O) also would provide etchback of both glass and epoxy. The objective of this project was to evaluate the feasibility of etching back both the epoxy smear and the glass fibers in multilayer PWB holes using a plasma process.

\section{ACTIVITY}

An extensive literature search was conducted along with consultation and a trip to several manufacturers of plasma equipment. For evaluation, various multilayer panels were laminated, drilled, and plasma treated. All panels were sectioned and scanning electron microscope (SEM) photographed to show the effects of various plasma processes.

The plasma process is a condition whereby a gas can be ionized at the atomic level by an electric field. The gas becomes reactive to surfaces it. contacts. The presence of ions and free radicals in a plasma makes the gas very reactive and thus very unstable. Unless energy is supplied continuously to maintain the plasma, it will degenerate quickly into an ordinary gas.

Plasma etching systems have three basic units: a reactor chamber, which holds the pieces to be etched; a radio-frequency ( $r f$ ) generator, which supplies energy for creating plasmas within the reactor; and a control system for monitoring and controlling the gas flow, time, vacuum pressure, and power requirements.

Depending on the type of etching desired, there are two types of reactor chambers commercially available. These chambers consist of cylindrical reactors and planar reactors. In a cylindrical reactor, parts stand erect during etching. The reagent gas is introduced through the bottom of the chamber and flows toward the gas exhaust at the top. Parts receive bombardment from the plasma gas in all directions. With a planar reactor, parts to be etched lie side-by-side on a flat, rectangular plate. This plate is the lower of two electrodes that create plasmas in the reactor. 
The top electrode produces a concentrated etching plasma that is directed at specific sites. The planar reactor etches in only one direction.

The most suitable reactant gases, based on industry studies, for use on epoxy/glass substrates were carbon tetrafluoride ( $\mathrm{CF}_{4}$ ) and silicon tetrafluoride $\left(\mathrm{SiF}_{4}\right)$. Both of these gases work equally well; however, Bendix chose not to use $\mathrm{SiF}_{4}$ in these studies because of potential danger upon exposure to personnel in the event of leakage. When the gas contacts water, it forms hydrofluoric acid. All subsequent work was done with $\mathrm{CF}_{4}$ and oxygen mixtures. The oxygen was added to increase the reactive etch rate. Carbon tetrafluoride is an inert gas which presents no safety or health problems.

Because of the need to etch in all directions within a hole wall, the cylindrical design reactor chamber was chosen for this study. An IPC Model 4000 manufactured by Dionex Corporation, Hayward, CA was selected in order to handle the large panel sizes. This machine has a $0.6-$ by $0.9-\mathrm{m}$ aluminum chamber which is unaffected by the carbon tetrafluoride gas mixtures. Samples were placed in the chamber at $26.7 \mathrm{~Pa}$ pressure with $900 \mathrm{~W}$ of rf power and processed under the following conditions:

- 30 percent $\mathrm{CF}_{4} / 70$ percent 0,10 minutes;

- 30 percent $\mathrm{CF}_{4} / 70$ percent 0,15 minutes;

- 30 percent $\mathrm{CF}_{4} / 70$ percent 0,30 minutes;

- 50 percent $\mathrm{CF}_{4} / 50$ percent 0,15 minutes; and

- oxygen plasma only, 15 minutes.

SEM photographs (Figures 1 through 5) show the effects of these variables. The blend of 30 percent $\mathrm{CF}_{4} / 70$ percent $O$ for 15 minutes (Figure 2) appears most suitable for etching epoxies; however, it should be noted that the glass fibers are protruding. This inability to etch glass fibers lends this system more adaptable to a smear removal process rather than true etchback, where both epoxies and glass fibers are etched.

These same panels are shown in the bottom of Figures 1 through 5 after copper plating. The blend of 30 percent $\mathrm{CF}_{4} / 70$ percent $O$ for 10 to 15 minutes (Figures 1 and 2 ) shows acceptable smear removal. The other blends and times allow too much glass fiber protrusion which causes excessive folding of the electroplate.

Another alternative with the plasma etchback approach is to etch the glass fiber protrusions using conventional hydrofluoric acid after the plasma treatment has been performed. The result of 


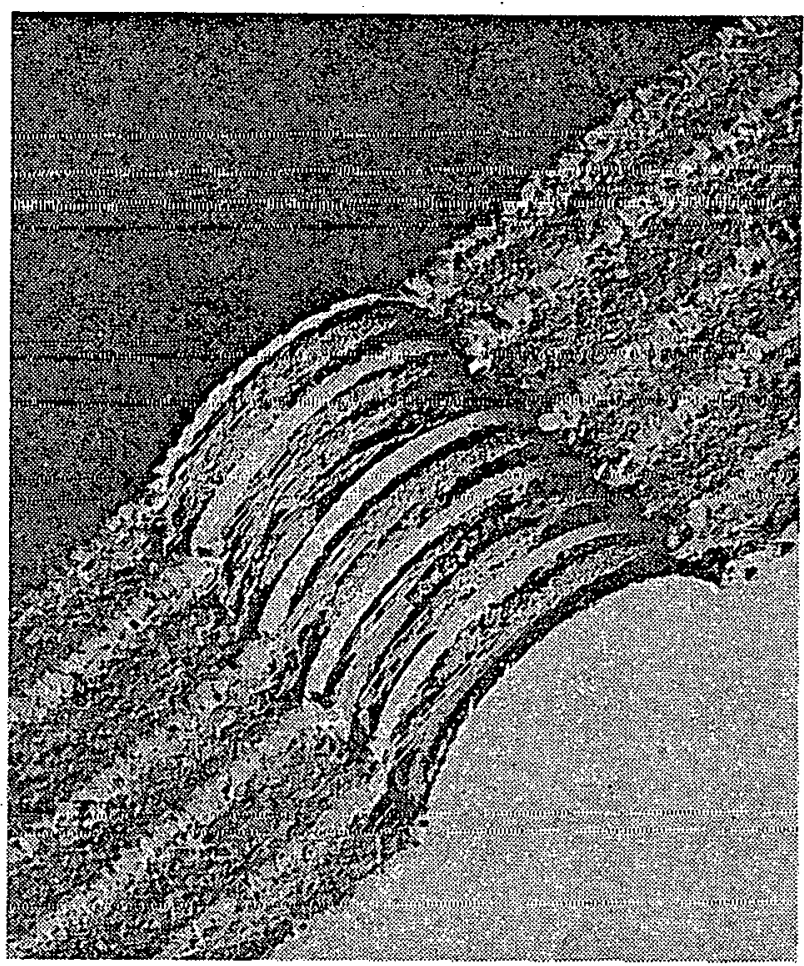

SEM, 50X

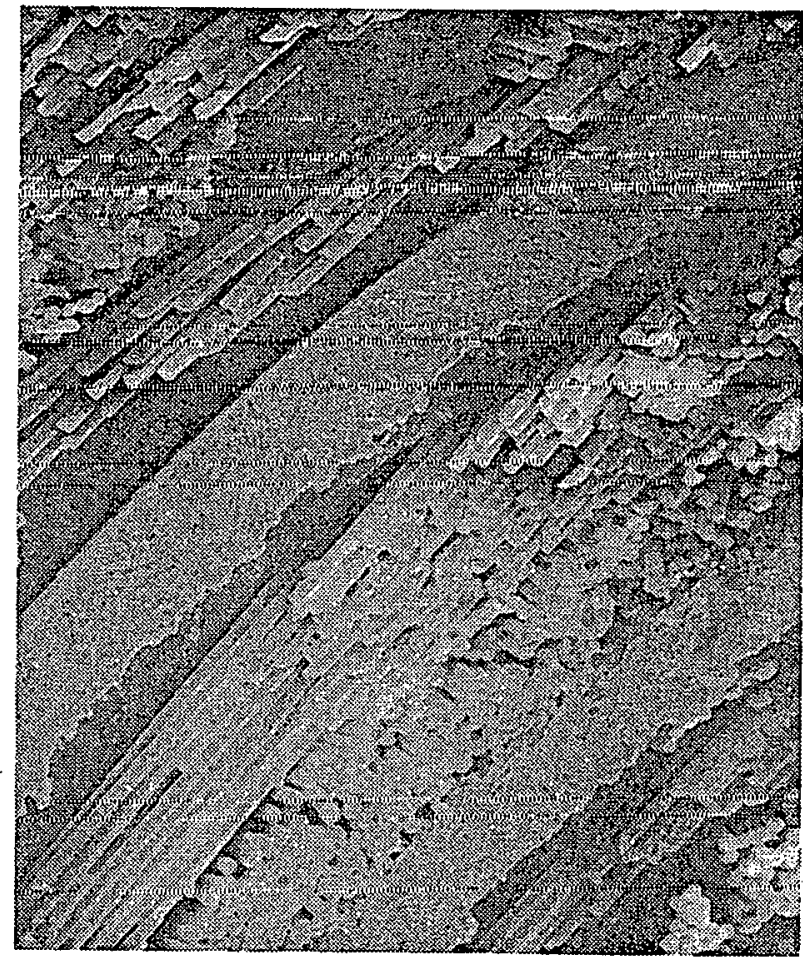

SEM, $300 \mathrm{X}$

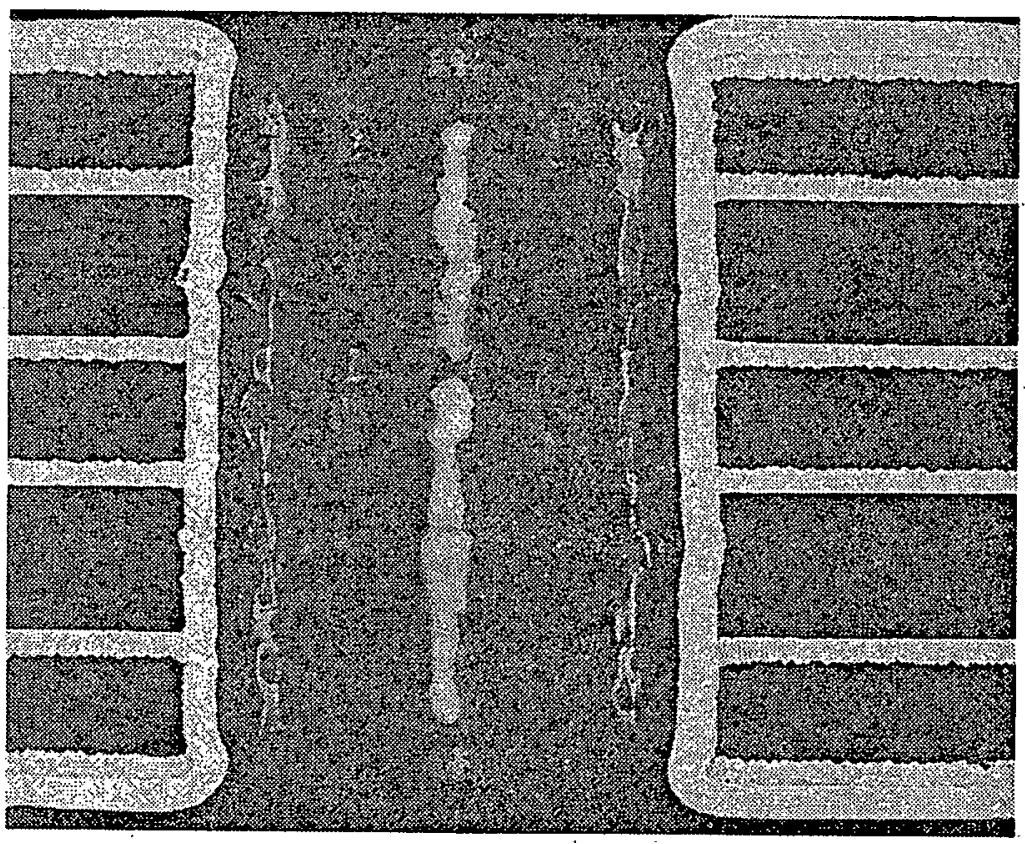

CROSS-SECTIONED PLATED-

THROUGH HOLE ELECTRO-

PLATED WITH Cu TO SHOW

SMEAR REMOVAL, 80X.

Figure 1. Multilayer PWB Plasma Etched for 10 Minutes With 30 Percent $\mathrm{CF}_{4} / 70$ Percent $\mathrm{O}$ 


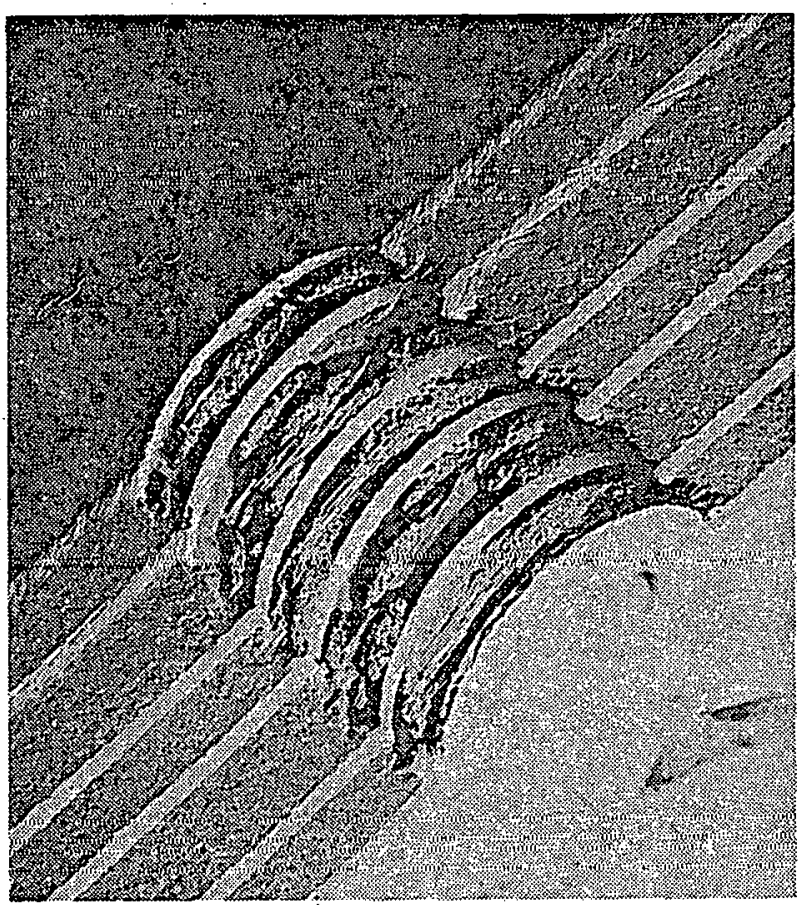

SEM, 50X

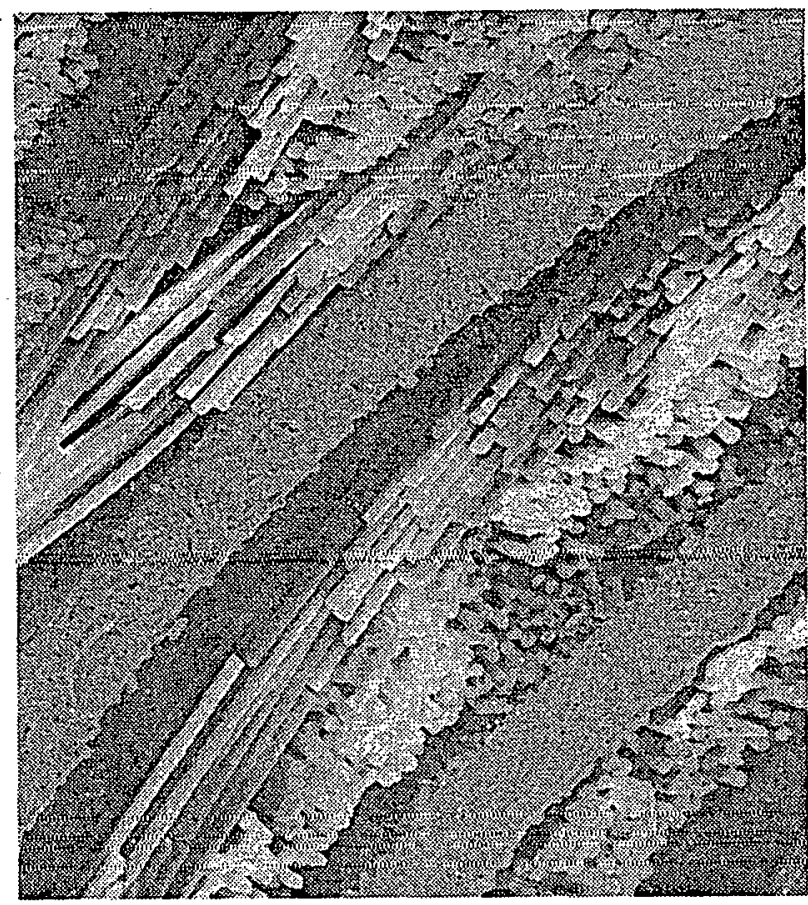

SEM, $300 \mathrm{X}$

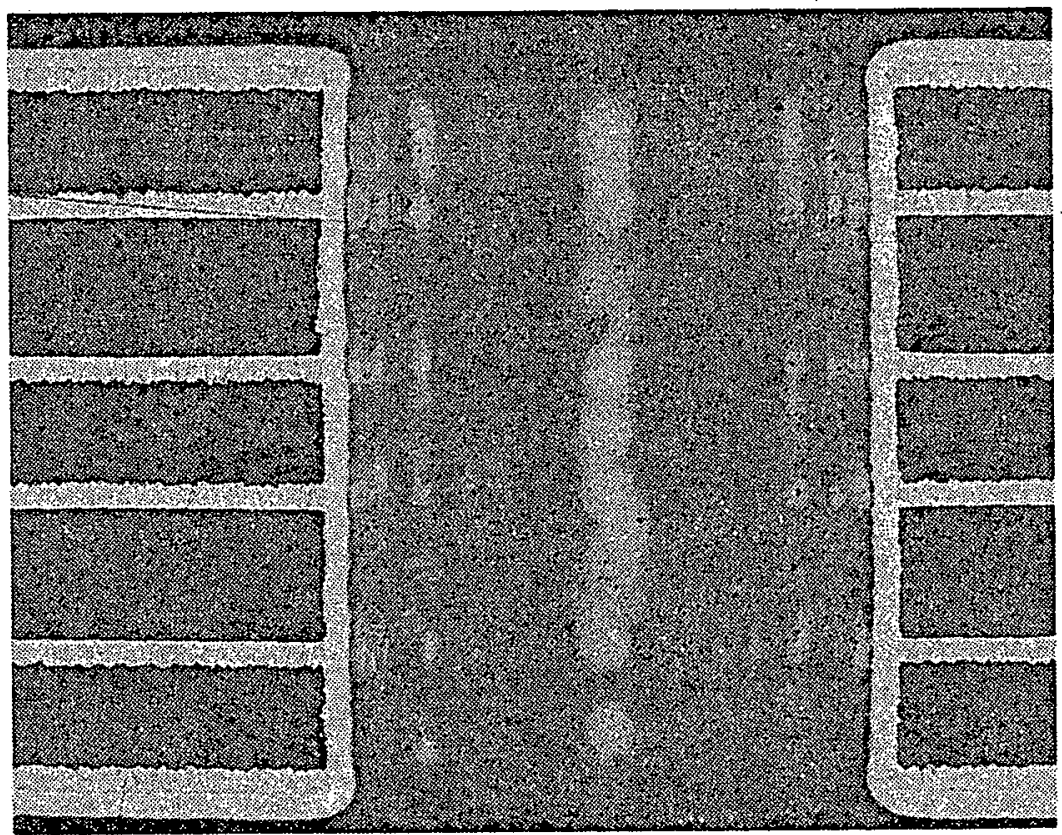

CROSS-SECTIONED PLATEDTHROUGH HOLE ELECTRO: PLATED WITH Cu TO SHOW SMEAR REMOVAL, 80X.

Figure 2. Multilayer PWB Plasma Etched for 15. Minutes With 30 Percent $\mathrm{CF}_{4} / 70$ Percent $\mathrm{O}$ 


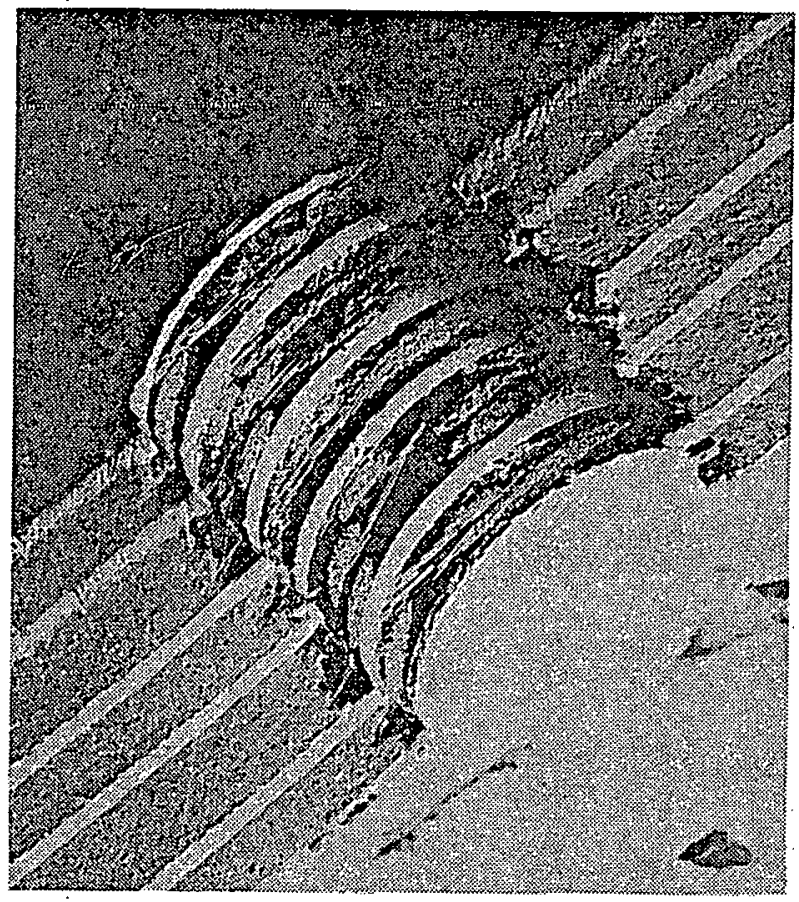

SEM, $50 X$

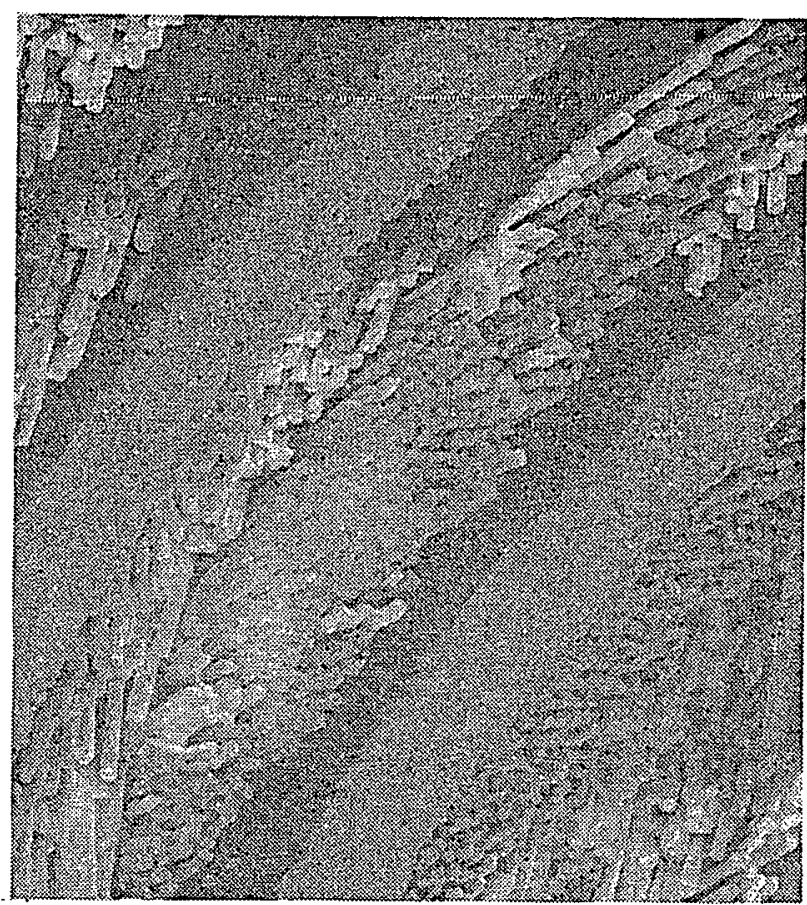

SEM, 300X

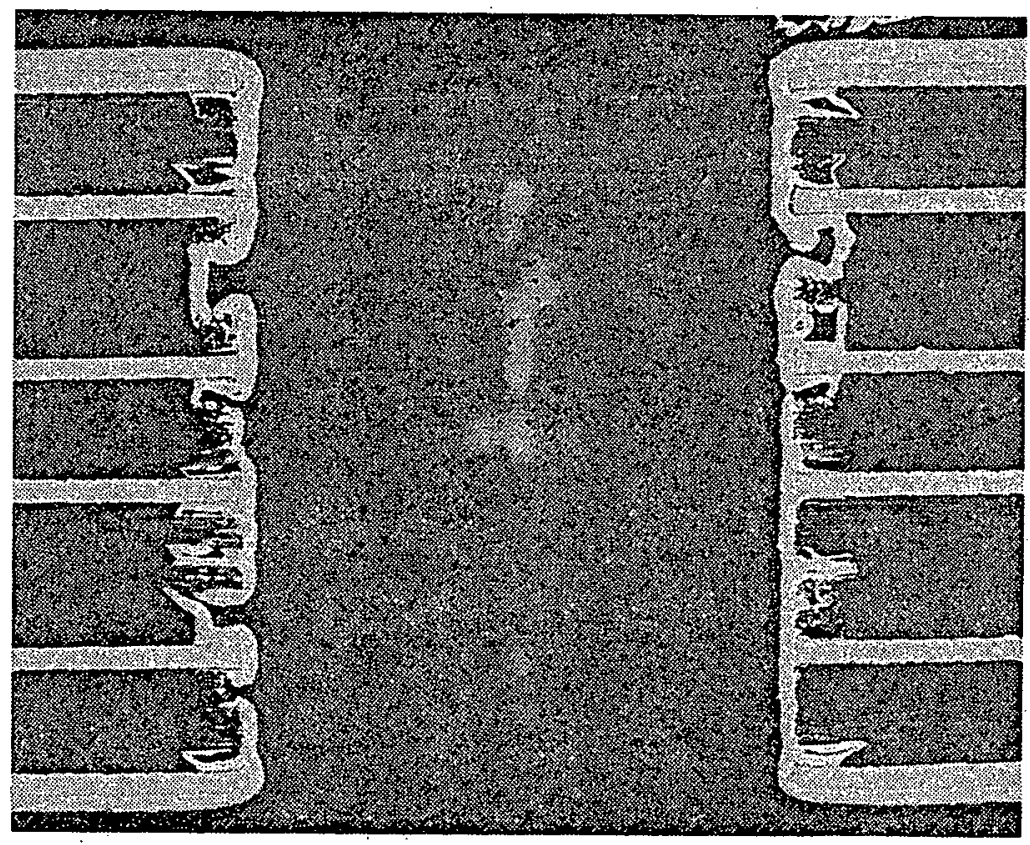

CROSS-SECTIONED PLATEDTHROUGH HOLE ELECTROPLATED WITH Cu TO SHOW SMEAR REMOVAL, 80X.

Figure 3. Multilayer PWB Plasma Etched for 30 Minutes With. 30 Percent $\mathrm{CF}_{4} / 70$ Percent $\mathrm{O}$ 


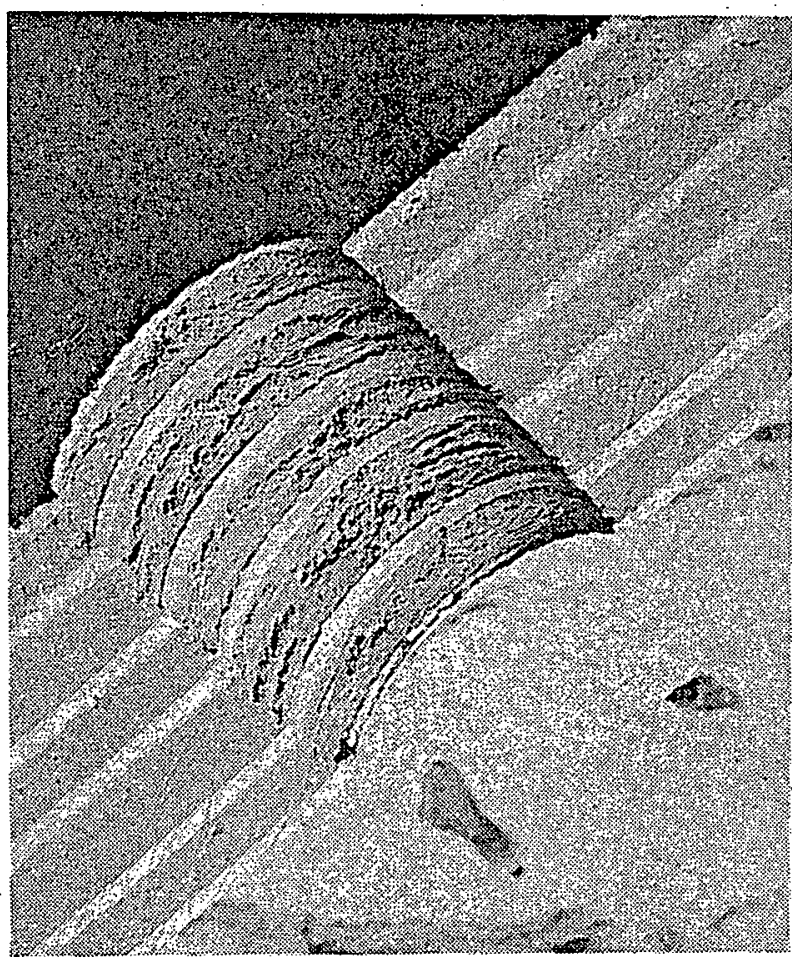

SEM, $50 \mathrm{X}$

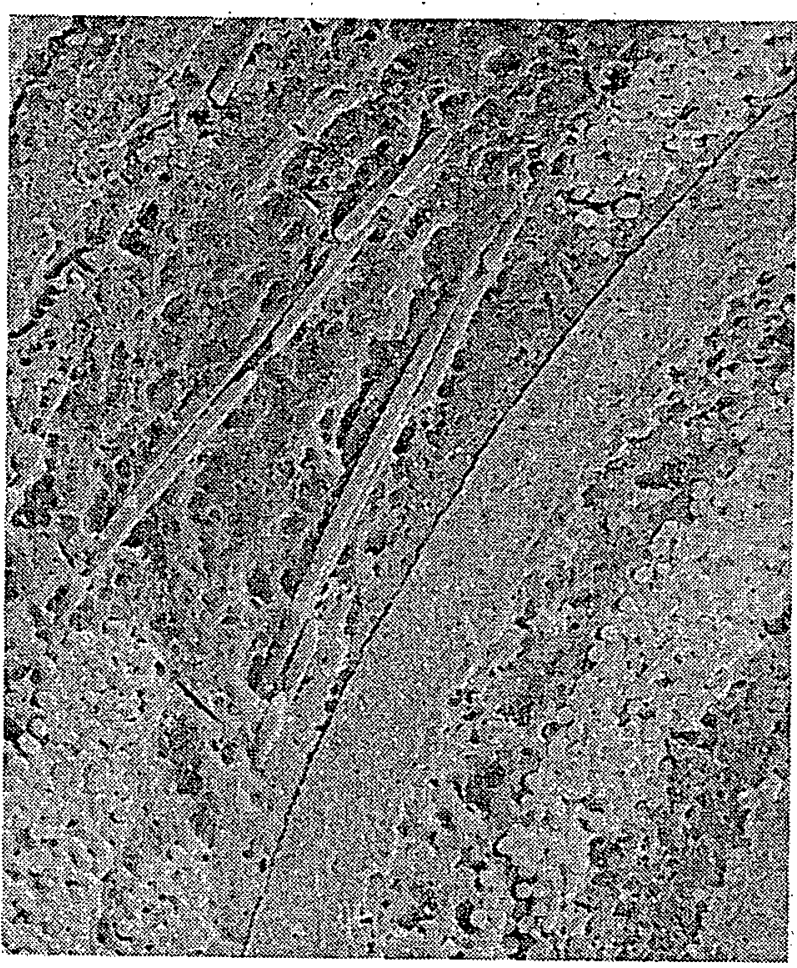

SEM, $300 \mathrm{X}$

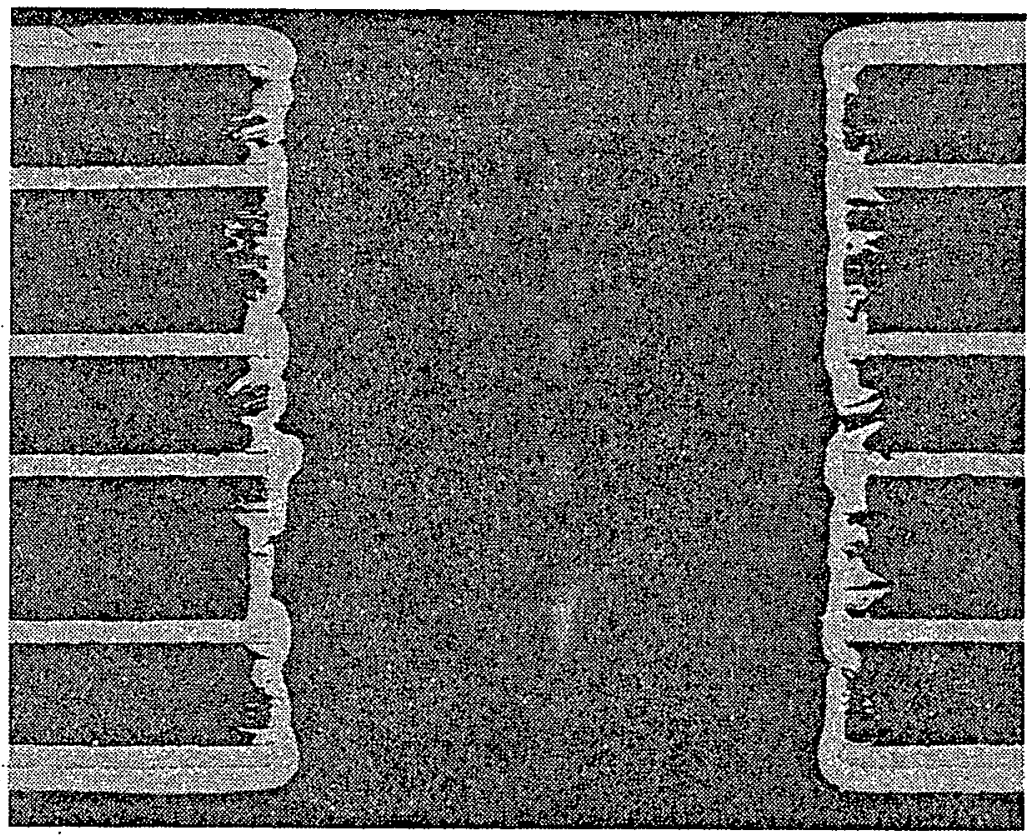

CROSS-SECTIONED PLATEDTHROUGH HOLE ELECTROPLATED WITH Cu TO SHOW SMEAR REMOVAL, 80X.

Figure 4. Multilayer PWB Plasma Etched for 15 Minutes With 50 Percent $\mathrm{CF}_{4} / 50$ Percent. 0 


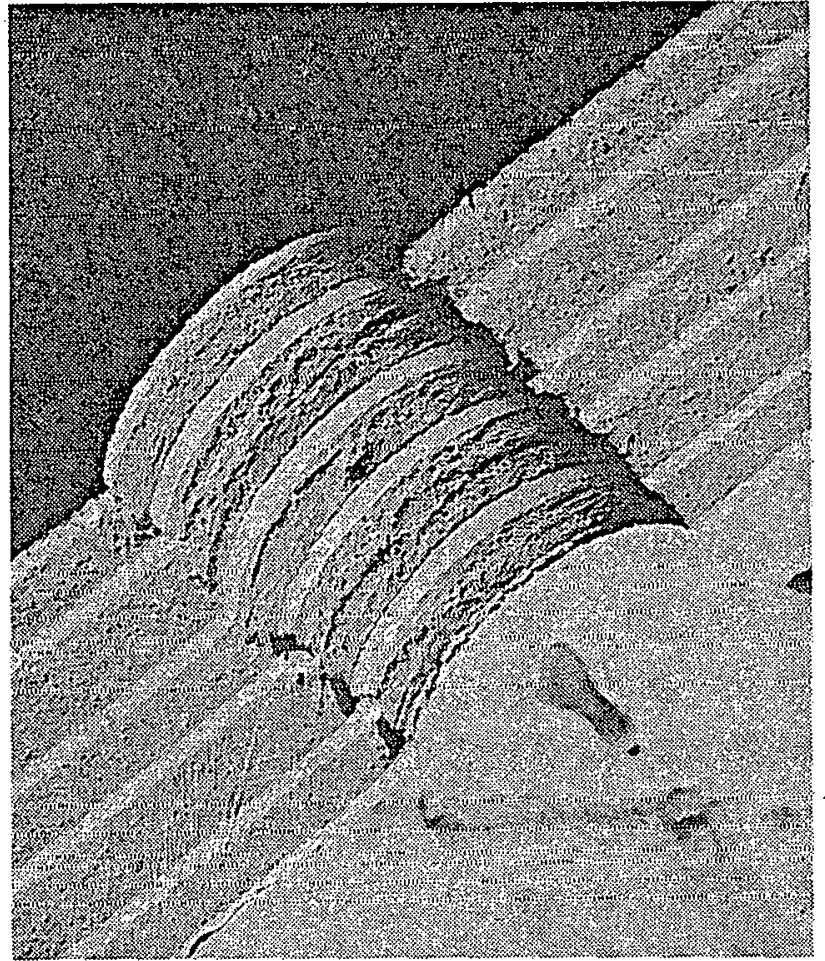

SEM, $50 \mathrm{X}$

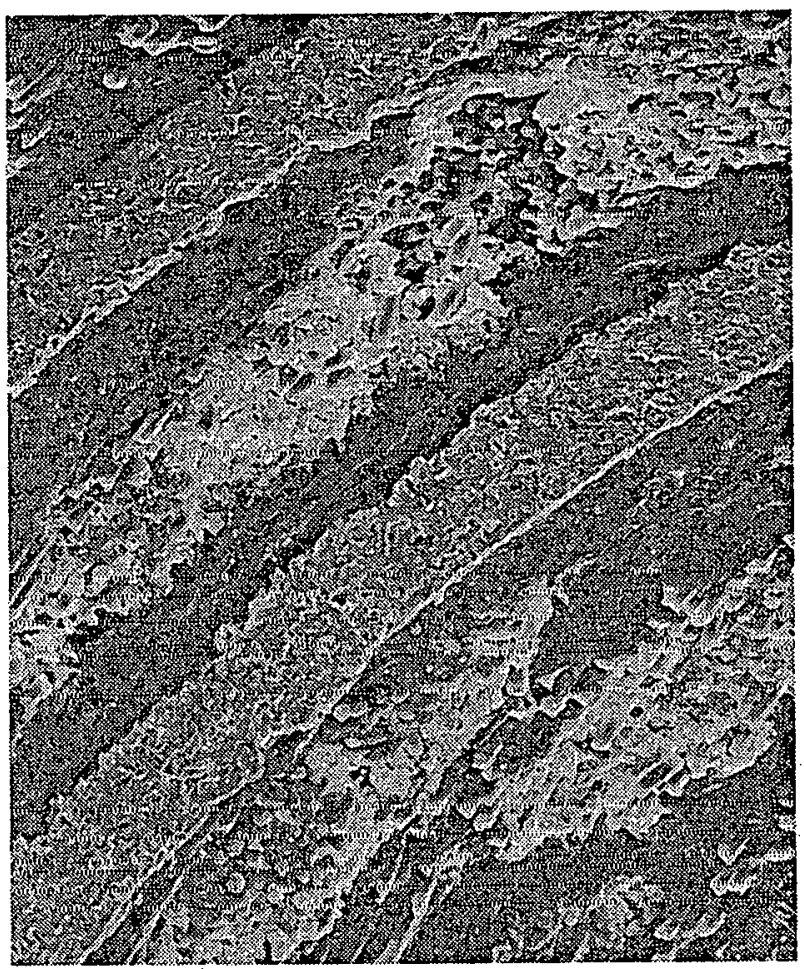

SEM, $300 \mathrm{X}$

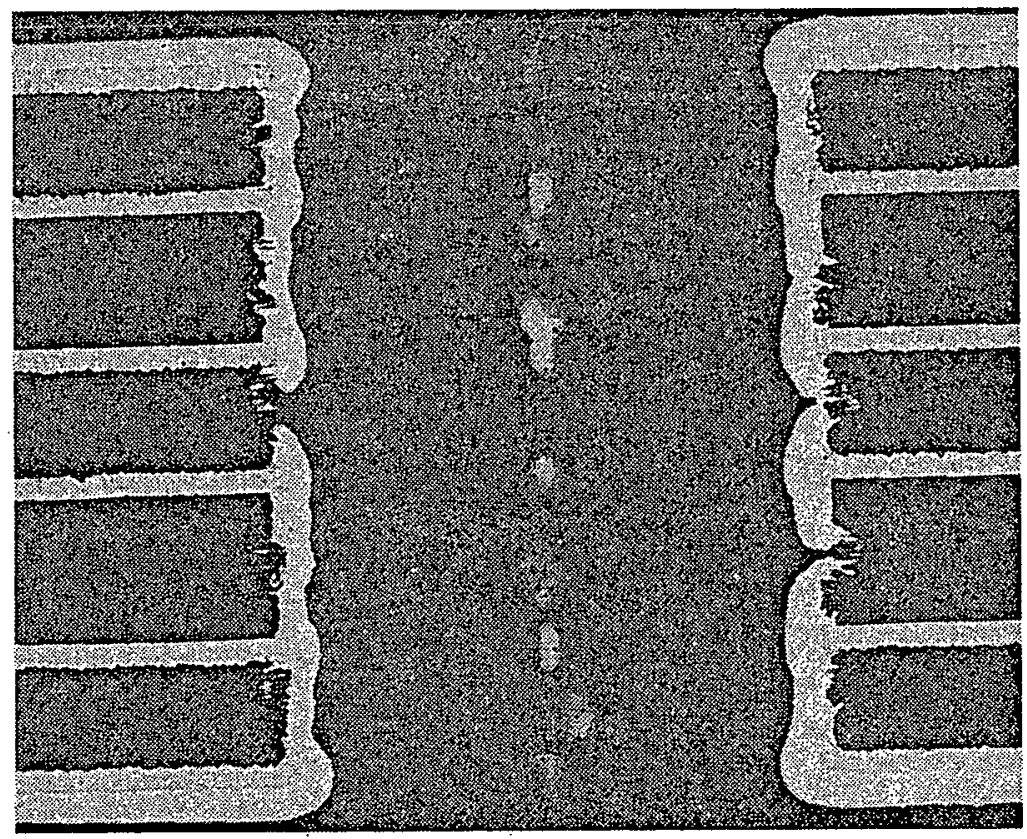

CROSS-SECTIONED PLATEDTHROUGH HOLE ELECTROPLATED WITH CU TO SHOW. SMEAR REMOVAL, 80X.

Figure 5: Multilayer PWB Plasma Etched for 15 Minutes With Oxygen Only 
this method is illustrated in Figure 6 in which a panel was plasma treated in 30 percent $\mathrm{CF}_{4} / 70$ percent $O$ for 15 minutes followed by a 30 second dip in hydrofluoric acid. This approach does not meet all of the objectives for epoxy multilayer boards since one-half of the wet etch system is still retained.

Although epoxy/glass boards would not necessarily benefit from this plasma and hydrofluoric acid system, high temperature materials could if a true etchback is needed. The chromic acid used to etch epoxies will not affect some of the high temperature resin systems. Manufacturers of triazines and polyimides claim no smear removal is necessary, because the resins do not melt during drilling; however, plasmas could be used if further investigation reveals smearing. Figure 7 shows the effect of plasmas on the surface of three triazine laminates. Figure $7 \mathrm{~A}$ represents an untreated laminate, while Figures $7 \mathrm{~B}$ and $7 \mathrm{C}$ were plasma treated as follows:

$$
\begin{aligned}
& \text { dry air, } 200 \mathrm{~W}, 80 \mathrm{~Pa}, 2 \mathrm{~h} \text {; and } \\
& \text { oxygen, } 200 \mathrm{~W}, 80 \mathrm{~Pa}, 2 \mathrm{~h} .
\end{aligned}
$$

This investigation shows that plasma techniques will cause erosion and resin removal of high-temperature laminates that would otherwise not be affected by conventional smear removal techniques. This study was conducted only on the surface of the laminate; consequently, additional research would be required to develop a suitable process for these high temperature resin systems.

\section{ACCOMPLISHMENTS}

Plasma techniques can be used for smear removal; however, etchback involving both the epoxy and glass cannot be performed satisfactorily. The present wet chemistry techniques should be used until further investigation of smear versus etchback processes can be studied. In addition, efforts should be continued toward improving the chromic/hydrofluoric system. While plasma etchback is not feasible now, industry improvements should be monitored for future reconsideration.

\section{FUTURE WORK}

A comprehensive study including testing to failure should be conducted to evaluate the reliability of smear removal versus etchback in multilayer printed wiring boards. This study would be of benefit in evaluating the possibility of discontinuing the etchback process in favor of smear removal only. Also, further study should be conducted to determine if the high temperature resin systems require any smear removal or etchback. 


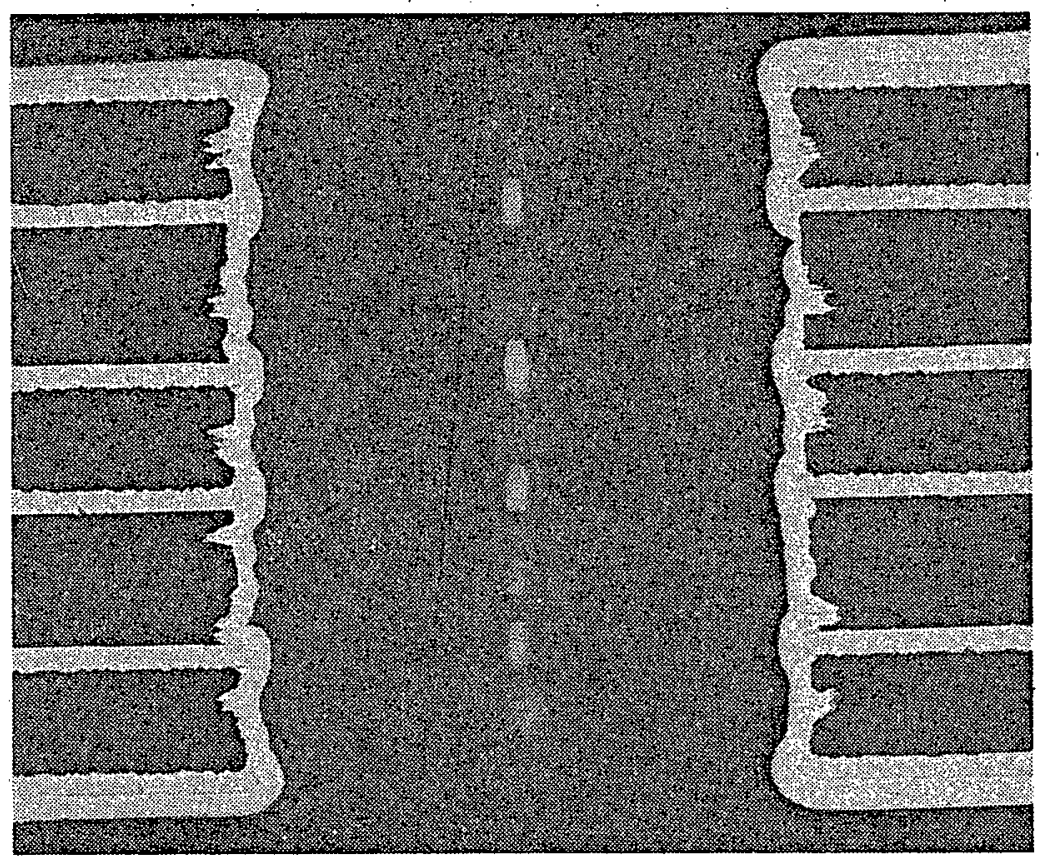

PLASMA ETCH:

30 PERCENT $\mathrm{CF}_{4}$ 70 PERCENT $O$

RINSE:

HF FOR $30 \mathrm{~s}$

Figure 6. Cross Section of Plated-Through Hole After Plasma Etching and HF Rinse to Remove Glass Fibers 


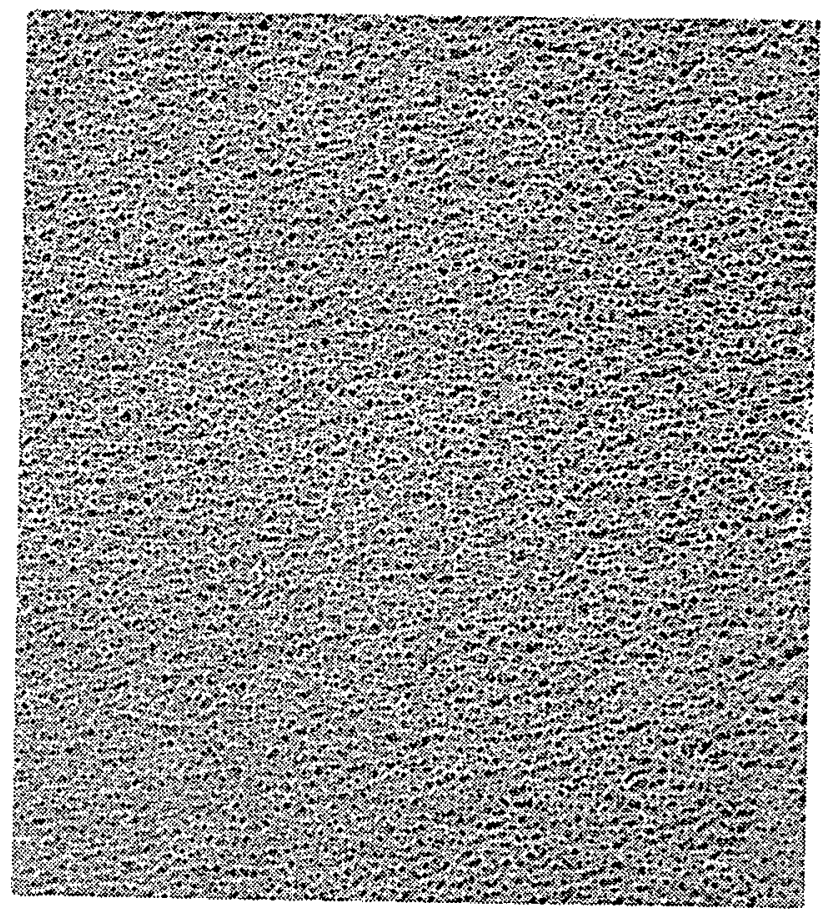

a. UNTREATED

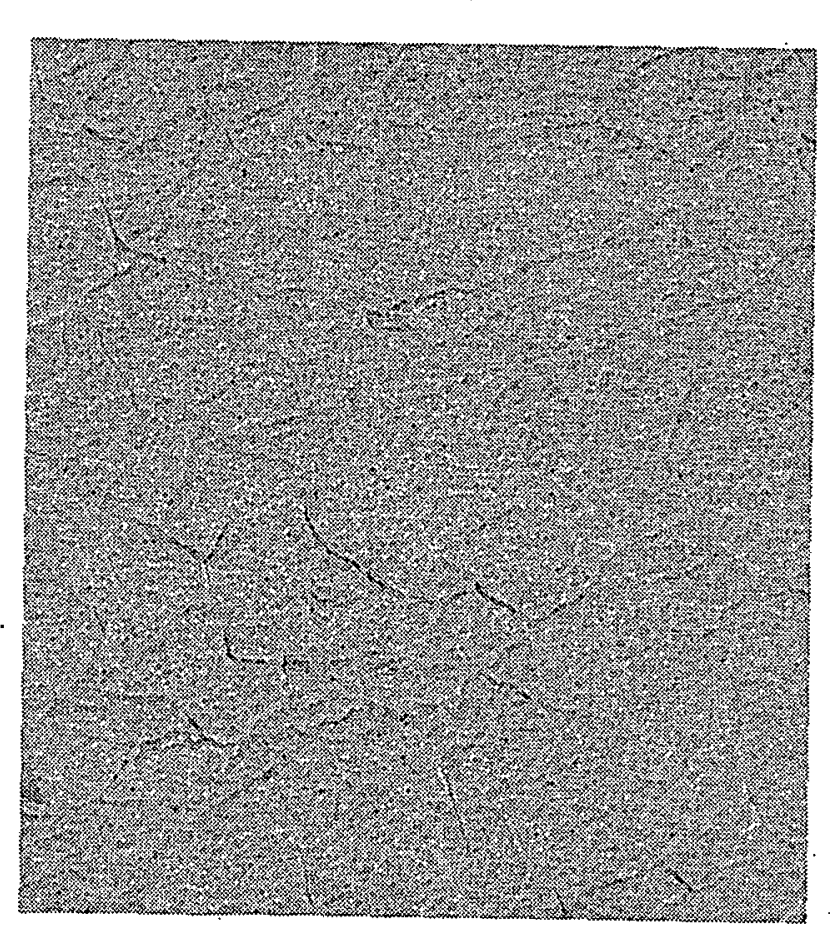

c. OXYGEN PLASMA

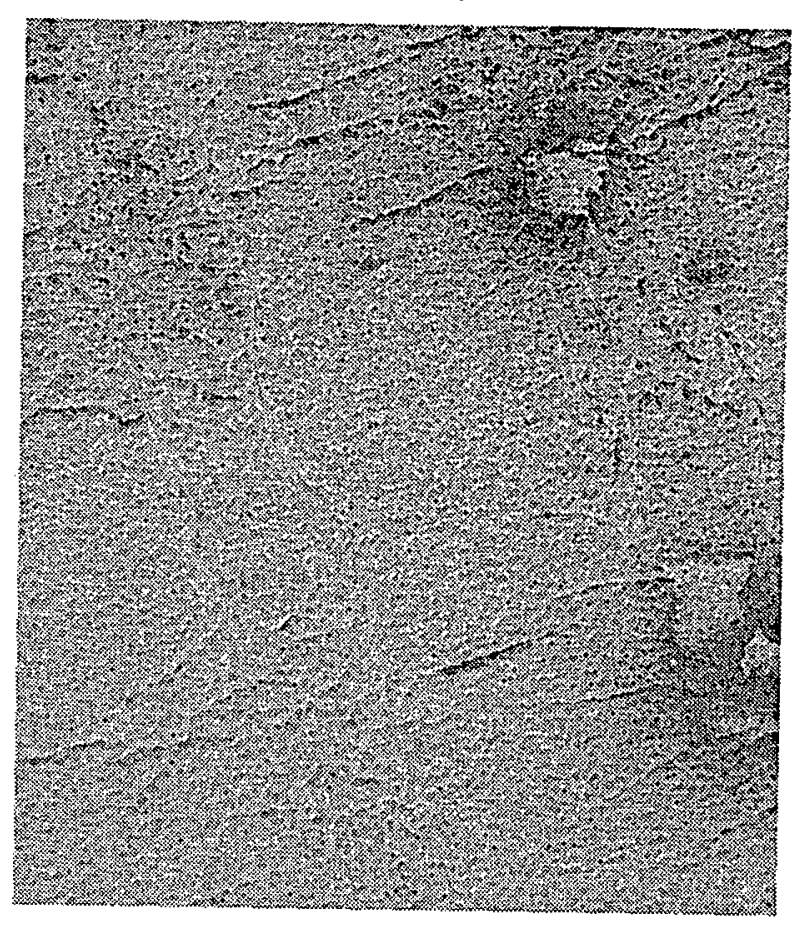

b. DRY AIR PLASMA

\title{
t.
}

b. DRY AIR PLASMA

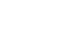


$\mathrm{BDX}-613-2458$

PLASMA ETCHBACK OF MULTILAYER PRINTED WIRING

BOARDS, F. L. Gentry, Final, June 1980.

Removal of epoxy smear and glass fiber protrusions in multilayer printed wiring board

holes was investigated. Gas plasma techniques, using a mixture of carbon tetrafluoride and oxygen, removed the epoxies; however, the

glass fibers were not affected.

-

ELECTRICAL: Plasma Etchback

PLASMA ETCHBACK OF MULTILAYER PRINTED WIRING

BOARDS, F. L. Gentry, Final, BDX-613-2458, June 1980 .

Removal of epoxy smear and glass fiber protrusions in multilayer printed wiring board holes was investigated. Gas plasma techniques, using a mixture of carbon tetrafluoride and oxygen, removed the epoxies; however, the glass fibers were not affected.

PLASMA ETCHBACK OF MULTILAYER PRINTED WIRING BOARDS, F. L. Gentry, Final, BDX-613-2458, June 1980.

Removal of epoxy smear and glass fiber protrusions in multilayer printed wiring board

holes was investigated. Gas plasma techniques, - using a mixture of carbon tetrafluoride and

I oxygen, removed the epoxies; however, the glass fibers were not affected. 